\title{
Nellcor Stat Cap differentiates oesophageal from tracheal intubation
}

\author{
Paul D Sutherland, Michael Quinn
}

\begin{abstract}
A trial of the Nellcor Stat Cap, which detects exhaled carbon dioxide, as an aid to determining whether endotracheal tubes are placed in the oesophagus or the trachea, was carried out in the neonatal unit of this hospital. Twenty five neonates, with a mean (range) gestational age of 33 (24-42) weeks and a mean (range) birthweight of $2.17(0.54-4 \cdot 1) \mathrm{kg}$ were studied over two months. These babies underwent a total of 58 intubations and 20 suspected self-extubations. The Nellcor Stat Cap was easy to use. It confirmed clinical findings on 20/20 occasions when the endotracheal tube was in the oesophagus and on $57 / 58(98 \%)$ occasions when it was in the trachea. On $14 / 78(19 \%)$ occasions the machine provided helpful additional information in reaching a decision on the adequacy of tube placement.

Failure to detect rapidly accidental oesophageal intubation or unintentional tracheal extubation can result in rapid deterioration of the condition of ventilated newborns. The machine is a valuable aid to intubation and rapid diagnosis of selfextubation.

(Arch Dis Child 1995; 73: F184-F186)
\end{abstract}

Keywords: intubation, self-extubation, Stat Cap, ventilated newborns.

Tracheal intubation of newborns for intermittent positive pressure ventilation or for access to the trachea for suction of meconium frequently saves lives. Unrecognised oesophageal intubation and accidental extubation of ventilated babies often causes profound hypoxia. Usually, defining tube position is straightforward, but clinical signs can be misleading. ${ }^{1-5}$

Capnography is routinely used in anaesthetic practice to assess the adequacy of ventilation and to confirm endotracheal tube placement. ${ }^{167}$ It is not widely used in newborns as they have very small tidal volumes and capnography machines are usually expensive and not portable. The success of a disposable carbon dioxide detector has been described in babies and children weighing over $2 \mathrm{~kg}^{89}$ We carried out a trial of the Nellcor Stat Cap in a neonatal intensive care unit, with a population including smaller babies, to determine whether it is accurate in defining endotracheal tube position and whether it is clinically useful.

\section{Methods}

The Nellcor Stat Cap (Nellcor UK) is a portable, battery operated capnometer and weighs $0.65 \mathrm{~kg}$. It has a warm up time of about 5 seconds. It detects carbon dioxide in gas passing through a sensor by infrared absorption. It has a rapid response time and provides a semiquantitative measure of exhaled carbon dioxide partial pressure. The manufacturers have no experience of its use in children under 3 years of age or weighing less than $10 \mathrm{~kg}$. The manufacturer's recommendations are that each sensor should be used for single patient use only.

Twenty five consecutive newborns who required intubation either on the neonatal intensive care unit or on the labour ward were studied. Their mean (range) gestational age was 33 weeks ( 24 to 42 weeks) and their mean (range) birthweight was $2.17 \mathrm{~kg}(0.54$ to $4 \cdot 10 \mathrm{~kg}$ ). Eight weighed less than $1.5 \mathrm{~kg}$ and four less than $1 \mathrm{~kg}$. Twelve of the babies were intubated and ventilated for hyaline membrane disease of whom six developed chronic lung disease; three were ventilated for transient tachypnoea of the newborn, one for a tracheooesophageal fistula, and nine were intubated for postnatal resuscitation, of which five were suspected meconium aspirations. Whenever an intubation was performed or the question of self-extubation raised, the Stat Cap machine was used in conjunction with clinical judgment.

The Stat Cap sensor was placed between a Laderal bag and the endotracheal tube and the baby was hand ventilated (figure). The sensor, which has a dead space of $4 \mathrm{ml}$, was removed as soon as it had indicated endotracheal tube position. An intermittent detection of carbon dioxide in time with ventilation for at least four breaths indicated tracheal intubation, and the absence of this pattern indicated oesophageal intubation. Each sensor was used for single patient use. Whenever the machine was used, the clinician completed a proforma describing the circumstances of the event, whether the machine was easy to use, whether it confirmed clinical findings, and whether it added to the clinical findings. As its role has not been defined before, clinicians were encouraged to base their management decisions on their clinical findings rather than on the information provided by the Stat Cap.

\section{Results}

Among the group of 25 babies, there were 58 intubations, of which 55 were tracheal and 


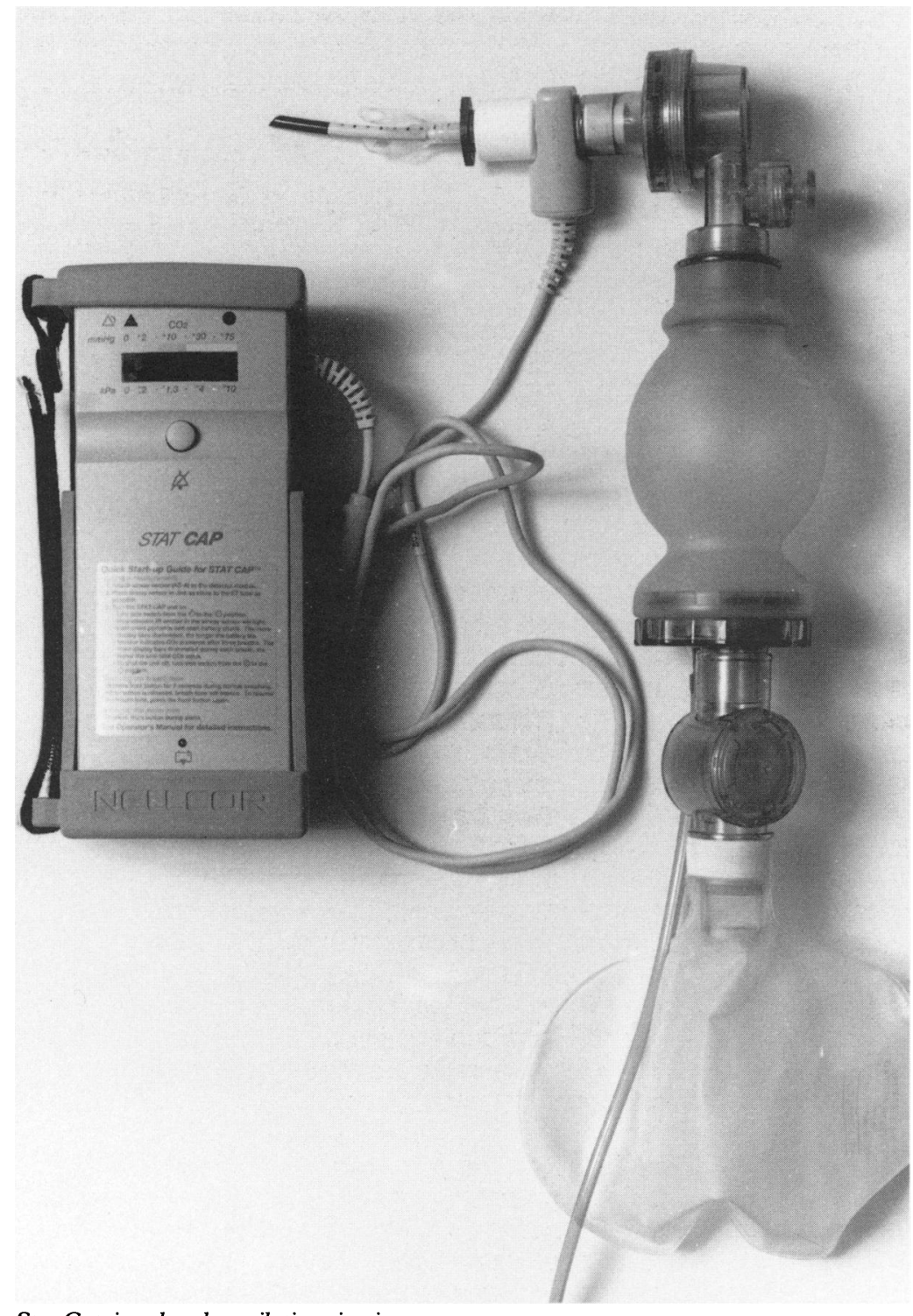

Stat Cap in a hand ventilating circuit.

three were accidental oesophageal intubations. There were 20 suspected accidental extubations of which 17 were confirmed and three were found not to have extubated. Of the 58 occasions when the tube was in the trachea, the Stat Cap correctly confirmed the clinical findings in $57(98 \%)$. Of the 20 occasions in which the endotracheal tube was in the oesophagus, the Stat Cap correctly confirmed all of them. The one occasion when the Stat Cap gave an erroneous result was in a baby of 28 gestational weeks and weighing $1.03 \mathrm{~kg}$. This baby had mild respiratory distress syndrome and was intubated in the labour ward following bag and mask ventilation at 5 minutes of age.

In all but one case the machine was easy to operate. In this case the clinician had difficulty assembling the sensor to its mount.

In most cases the clinical findings were obvious and the Stat Cap confirmed them. However, in nine of the $58(15 \%)$ intubations and in five of the $20(25 \%)$ possible accidental extubations, the Stat Cap provided valuable additional information to the clinician. On two occasions, the endotracheal tube was seen to pass through the vocal cords, auscultation of the chest was ambiguous, and there was a small increase in oxygen saturation. The Stat Cap detected no carbon dioxide, the tube was removed, and bag and mask ventilation followed by reintubation with an endotracheal tube of the same length ensured a rapid recovery.

In a third baby that had self-extubated, hand ventilation provided some increase in saturation, but the Stat Cap confirmed that the endotracheal tube was not in the trachea. On another occasion, reintubation of a 26 week gestational age baby, who had very high ventilatory requirement, was performed by a senior member of the medical staff. Auscultation and chest movement were ambiguous and, despite hand ventilation, the oxygen saturation did not rise. The clinician was about to attempt reintubation of the baby, but the Stat Cap detected the intermittent presence of carbon dioxide; the tube was left in place and eventually the baby's condition improved.

\section{Discussion}

Undiagnosed oesophageal intubation continues to figure prominently in anaesthetic morbidity and mortality. ${ }^{1011}$ There are many methods available to determine endotracheal tube position, but rapidly discovering whether an endotracheal tube is in the oesophagus or trachea is not always straightforward. Visualisation of the tube passing through the vocal cords is considered to be a 'gold standard', but is sometimes difficult in newborns and does not help identify accidental selfextubation. During two of the intubations in this study, the endotracheal tube was seen to pass through the vocal cords, but was found to be oesophageal. The clinical signs of chest movement and auscultation of the lung fields and epigastrium during ventilation, although often accurate in defining tube position, can be misleading. ${ }^{1-5}$ Eventually the clinical response of the baby confirms endotracheal tube placement. However, clinical improvement after correct positioning in the trachea is not always rapid and the deterioration after incorrect placement is best avoided by earlier recognition of tube placement. Linko et al ${ }^{7}$ found that in 18 out of 20 patients, after deliberate intubation of the oesophagus and trachea, ventilation of the oesophagus caused alveolar gas exchange in the lungs. This may account for the small improvement in three of our babies who were intubated in the oesophagus.

We have found that for a wide range of gestational ages and weights, the Nellcor Stat Cap is easy to use and reliably confirms tube position. It frequently provides useful additional information on tube placement, particularly in cases of accidental self-extubation. The Stat Cap produced a false negative result on one occasion: although small $(1.02 \mathrm{~kg})$, there were four smaller babies in the study for which the Stat Cap did give a correct result. As this intubation had followed 5 minutes of bag and mask ventilation in the labour ward, the failure might have been the result of dilution of the small expiratory volume with fresh gas in the sensor, combined with hyperventilation 
reducing the end-tidal carbon dioxide partial pressure. Failures of capnometry to detect tracheal intubation have been described: with cardio-pulmonary arrest, ${ }^{12}{ }^{13}$ in which $\mathrm{CO}_{2}$ is not delivered from tissues to the lungs; severe bronchospasm, ${ }^{14}$ in which little or no alveolar gas exchange may occur; a large endotracheal tube leak in the presence of positive end expiratory pressure, ${ }^{15}$ in which expiratory gas can bypass the endotracheal tube; hyperventilation of a newborn ${ }^{9}$; and equipment failure. ${ }^{14}$

A Stat Cap can greatly aid diagnosis of tube placement. It may be of particular use in determining whether a baby has self-extubated, and during intubation of babies with a high ventilatory requirement when clinical response is often delayed. The Stat Cap is easy to carry, allowing it to be used in the delivery suite and it has rapid warm-up and response times. We feel that it may be of particular benefit for less experienced members of medical staff, who are often the first on the scene.

1 Birmingham PK, Cheney FW, Ward RJ. Esophageal in tubation. A review of detection techniques. Anesth Analg 1986; 65: 886-91.
2 Mizutani AR, Ozaki G, Benumof JL, Scheller MS. Auscultation cannot distinguish esophageal from tracheal passage of tube. $\mathcal{f}$ Clin Monit 1991; 7: 232-6.

3 Holland R, Webb RK, Runciman WB. Oesophageal intubation: An analysis of 2000 patients. Anaesth Intens Care 1993; 21 : 608-10.

4 Pollard BJ, Junius F. Accidental intubation of the oesophagus. Anasthes Intens Care 1980; 8: 183-6.

5 Howells TH, Riethmuller RJ. Signs of endotracheal intubation. Anaesthesia 1980; 35: 984-6.

6 Murray IP, Modell JH. Early detection of endotracheal tube accidents by monitoring $\mathrm{CO}_{2}$ in respiratory gas. Anaesthesiol 1983; 59: 344-6.

7 Linko K, Paloheimo M, Tammisto T. Capnography for Linko K, Paloheimo M, Tammisto T. Capnography for detection of accidental oesophagea

8 Bhende MS, Thompson AE, Cook DR, Saville AI. Validity of a disposable end-tidal carbon dioxide detector in verifying endotracheal tube placement in infants and children. Ann Emerg Med 1992; 21: 47-50.

9 Bhende MS, Thompson AE, Orr RA. Utility of an end-tidal carbon dioxide detector during stabilization and transport of critically ill children. Pediatrics 1992; 89: 1042-4

10 Utting JE. Pitfalls in anaesthetic practice. Br 7 Anaesth 1987; 59: 887-90

11 Solazzi RW, Ward RJ. The spectrum of medical liability cases. In: Pierce EC, Cooper JB, eds. International Anaesthesia Clinics. Boston: Little, Brown and Company, 1984: 43-59.

12 Kalenda $Z$. The capnogram as a guide to the efficiency of cardiac massage. Resuscitation 1978; 6: 259-63.

13 Falk JL, Rackow EC, Weil MH. End-tidal carbon dioxide concentration during cardio-pulmonary resuscitation. concentration during cardio-p

14 Dunn SM, Mushlin PS, Lind LJ, Raemer D. Tracheal intubation is not invariably confirmed by capnography. Anaesthesiol 1990; 73: 1285-7.

15 Markovitz BP, Silverburg M, Godinez RI. Unusual cause for an absent capnogram. Anaesthesiol 1989; 71: 992-3. 